\title{
Improvement of management in the housing- and-communal sphere in the green economy
}

\author{
Angela Mottaeva 1,2,* \\ ${ }^{1}$ Moscow State University of Civil Engineering, 129337, 26, Yaroslavskoye Shosse, Moscow, Russia \\ ${ }^{2}$ Moscow Region State University, 105005, Radio str, 10A, Moscow, Russia
}

\begin{abstract}
The relevance of the research subject is dictated by the poor quality of management at all the levels of the system of housing-andcommunal services in Russia, insufficient study of the specifics of management of the industry, and also by the need of the development of ways of the increase in management efficiency for the purpose of providing its development according to the requirements of the green economy. The mechanism and structural model of management of housing-and-communal services were developed. It will allow increasing the management quality in the organizations of housing-and-communal services in the context of its sustainable development, structural dynamics, features of manifestation of interrelations of its elements, and also to resolve some contradictions. Such contradictions exist among the purposes of the state (development of the competition in the market of housing-andcommunal services), purposes of commercial organization (making maximum profit), and purposes of population (receiving high-quality and cheap services). Moreover, the contradictions exist among the economical purposes, social interests and environmental priorities. The results of the research can be useful for the improvement of management in the housingand-communal sphere according to the principles of green economy.
\end{abstract}

\section{Introduction}

Development of the system of housing-and-communal services becomes impossible without the application of new forms, methods of management of the organizations. Therefore, the increase in the management efficiency is a relevant and very significant matter, both for the theory, and for the practice of management in this sphere of activity.

Poor quality of management at all the levels of the system of housing-and-communal services in Russia, insufficient study of specifics of management of this industry caused the need of the development of any ways of the increase in the management efficiency for the purpose of providing its recovery from the crisis and further development

In modern scientific literature, these matters are considered with different degree of readiness. The significant contribution to studying of quality and effective management of the enterprises and the organizations was brought by foreign scientists D. Aaker, R. Akoff, I. Ansoff, P. Druker, H. Iosikhara, D. Mercer, T. Peters and R. Waterman, A.J. Strinklend

* Corresponding author: angela-1309.m@yandex.ru 
and A. Thompson, F. Taylor, G. Mintsberg, G. Ford, G. Emerson, S. Young, and Russian: I.V. Bondarenko, V.A. Vinokurov, V.M. Kolpakov, V.I. Korolev, P.V. Magdanov, M.V. Melnik, A.G. Porshnev, B.A. Rayzberg, A. Svirina, etc.

In the sphere of housing-and-communal services, works of V.V. Akimkin, S.I. Bazhenov, S.N. Glazunov, P.A. Kantor, A.A. Martynov, G.A. Nikolaev, V.P. Pilyavsky, O.V. Serdyuk, V.Z. Chernyak, etc. are devoted to the steering problems.

In spite of the fact that the considerable quantity of scientific works is devoted to the theoretical bases of management, in their studying, incompleteness of conceptual provisions was revealed that complicates formation of the corresponding mechanisms, allowing to increase quality of management. In particular, there are not enough works in which the quality of management in the organizations of housing and communal services in the context of its development, structural dynamics, features of manifestation of interrelations of its elements is considered.

The solution of the designated problems is of scientific interest. It needs further theoretical and methodological justification, and also the implementation in relation to the present stage of the development of the market relations.

\section{Materials and Methods}

The achievement of quality of management of housing-and-communal services consists in the search of such description of the ratio of elements by which the degree of satisfaction of requirements is rather high. During the creation the management of housing-and-communal services, the assumption was made that all the elements which will enter model are in certain dependence and structurally and functionally connected among themselves. When developing the model of management, the technique of I.A. Togunov [1] who used a architectonic lattice as the structure of such model displaying the entity of inter-element couplings.

\section{Results}

The constructed model of management of housing-and-communal services allowed us to note that functional characteristics of elements are in the linear dependence from each other and form rather closed self-regulating system (Figure 1).

The revealed regularity allows presenting certain conditions of subjects of the market relations and systemacity of all the fundamental elements of the control system.

The managing company acts in the offered model as the main subject of management. Its advantages before other forms of government consist in higher professional structure of workers (in the conditions of licensing of the managing company) and in better resource providing. The least perspective is the form of self-government by residents of the house, in our opinion, it is acceptable only for small houses (to 10 apartments).

The central rhombus is the basic in the presented model, i.e. the quality of management is first of all. It is determined by the quality of purposes and tasks. The analysis of the programme documents on the development of housing-and-communal utilities revealed some shortcomings of formulation of the purposes at different levels of management of housing-and-communal utilities: the lack of the specification of the purposes, hierarchy; repetition, duplication, substitution of terms of tasks and purposes, etc. 


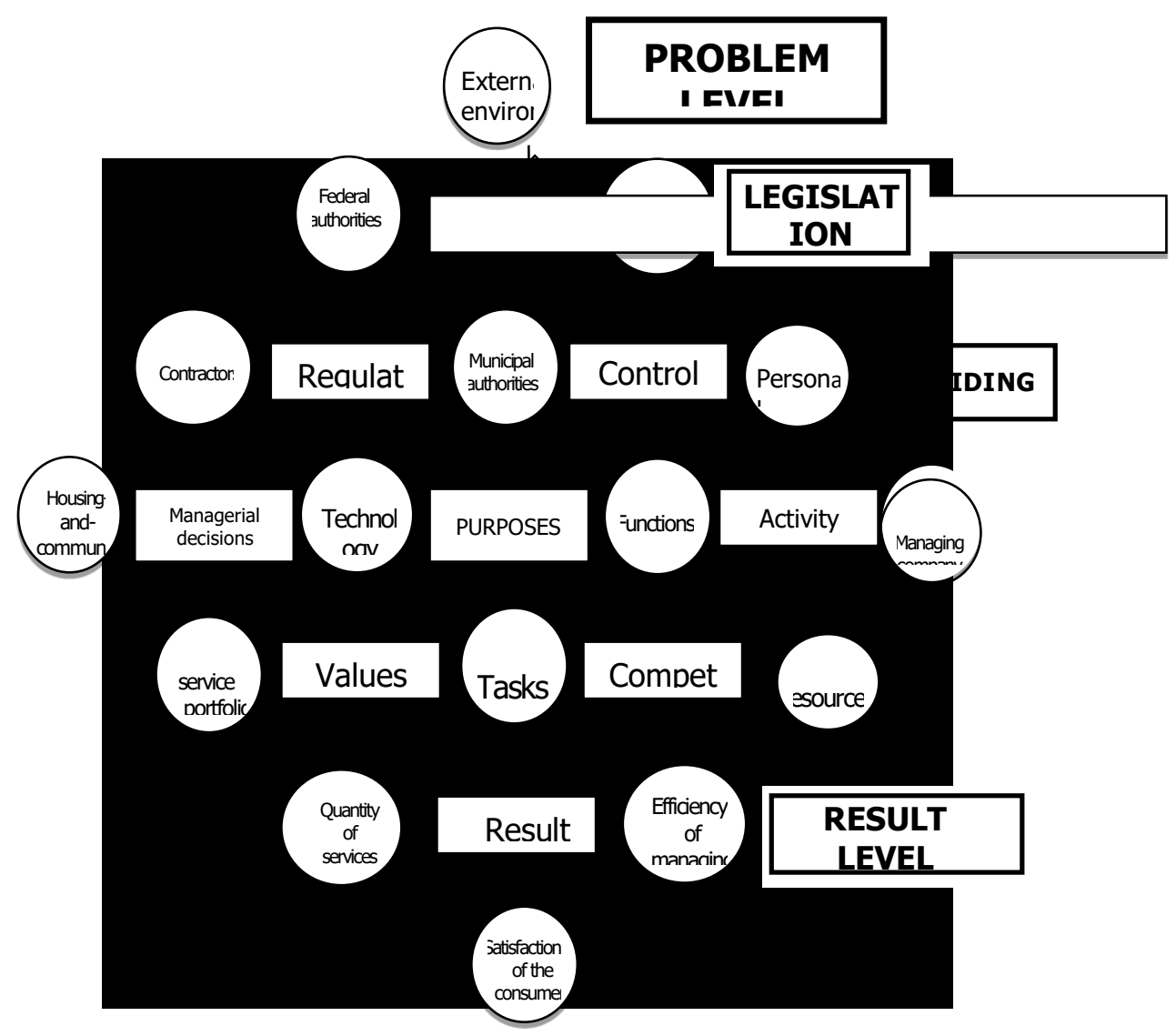

Fig. 1. Structural model of management of housing-and-communal services (made by the author)

On the basis of this model, it is offered to carry out the formation of the purposes of the first level proceeding from the interests of subjects of management: population, state, managing companies (Table. 1). 
Table 1. Formation of purposes according to the economic interests of the housing-and-communal services management subjects

\begin{tabular}{|l|l|}
\hline \multicolumn{1}{|c|}{ Consumers } & \multicolumn{1}{c|}{ Economic interests of management subjects } \\
\hline $\begin{array}{l}\text { Consumers of } \\
\text { housing-and- } \\
\text { communal services }\end{array}$ & $\begin{array}{l}\text { Decrease in the growth rates of service prices of housing-and-communal } \\
\text { utilities } \\
\text { Receiving quality services } \\
\text { Freedom of choice of managing organizations } \\
\text { Simplification of the procedure of receiving subsidies } \\
\text { Introduction of the differentiated payment for services within social norms } \\
\text { Development of targeted social support of the needy } \\
\text { Activation of programmes for resettlement of citizens from the hazardous } \\
\text { dwelling, etc. }\end{array}$ \\
\hline State & $\begin{array}{l}\text { Creation of the housing-and-communal services evidence-based standards } \\
\text { Strengthening of control of observance of the housing-and-communal services } \\
\text { standards } \\
\text { Decrease in expenses of the budget on housing-and-communal utilities } \\
\text { Target use of the budgetary funds } \\
\text { Growth of investments into the housing-and-communal utilities } \\
\text { Competition development } \\
\text { Increase in the social responsibility of business, etc. }\end{array}$ \\
\hline Management company & $\begin{array}{l}\text { Decrease in resource intensity of services } \\
\text { Increase in profit } \\
\text { Increase in solvent demand of the population } \\
\text { Decrease in tax burden for the small and medium business } \\
\text { Reduction of receivables } \\
\text { Increase in safety of business, etc. }\end{array}$ \\
\hline
\end{tabular}

The increase in the customers' (residents') satisfaction acts as the main objective of the managing organizations. In this regard, managing companies have to develop constantly appropriate programs concerning the consumer. We offer the programme of the increase in focus of management on the consumer, consisting of the following stages:

- The first stage. Collection of information about the customers (residents). This stage is rather difficult, labour-consuming and it also demands certain material inputs;

- The second stage. Informing the personnel of the organization on customer needs. At this stage, it is important to carry out the following actions: to develop the medium-term production programmes directed to continuous improvement of the control system in the field of orientation to the client; to improve internal competences of personnel; to provide vocational education of personnel;

- The third stage. Formation of the system of the internal business processes connected with the customer support. At this stage, the sequence of the processes is defined; their optimization is performed due to identification and elimination of the available problems; regulations of the processes increasing quality of the provided services are developed; the existing duty regulations are corrected.

- The fourth stage. Modification of production programmes on providing to the client new types of service and works.

- The fifth stage. Development of the system of estimates, the customer satisfaction of housing-and-communal services characterizing degree

One of the fundamental logical communication in model is the communication between the customer satisfaction and the efficiency of activity of the organization. The last is interested in the increase in the customer satisfaction as it promotes their greater attraction. Therefore, to win in competition for the customer, managing companies have to offer the customer better and cheaper services, and it, in turn, demands from the company of fulltime employment over the increase in the cost efficiency of activity of the organization. In case the managing company does not reach customer satisfaction, they (under the existing legislation) can change the managing organization. 
The feature of management of housing-and-communal services is shown in relationship between subjects and control objects. We consider that at management of the sphere of housing and communal services of the enterprises there are following levels of the subject and object relations:

1. Public authorities are the enterprises and the housing-and-communal utilities organizations;

2. Bodies of municipal authority are the enterprises and the housing-and-communal utilities organizations;

3. The enterprises and the organizations of the housing sector;

4. The consumer - managing organizations of housing and public utilities.

Each level has its concrete organizational structure.

On the basis of the constructed model of management of housing-and-communal services and system approach to management, the block diagram of the mechanism of improvement of quality of management is offered. The mechanism is accepted as set of forms, methods and tools by means of which interaction of subjects of management on provision of services and satisfaction of basic needs of the population is carried out (Figure 2).

The submitted block diagram of the mechanism of improvement of management quality unites the elements of external influence, forms, methods and instruments of internal selforganization of the control system. This scheme will allow increasing the quality of the provided services of the housing-and-municipal sphere by the organizations significantly.

\section{Discussion}

Many works of Russian and foreign scientists are devoted to the issues of relationship of managing organizations in the sphere of housing-and-communal services with consumers. But the problem of measurement of the degree of satisfaction with services demands carrying out additional scientific research.

Reaction of the consumer which cannot get any direct quantitative assessment and which is shown as the set of objective and subjective parameters, becomes the main criteria for evaluation of quality of service. So, assessment of service assumes comparison by consumers of their personal expectations with the level of perception of its quality by them. The satisfaction with the quality of the rendered services will depend on in what degree, according to the consumer, they correspond to the value. At the same time, the consumer imposes specific requirements (for housing-and-communal services is the uninterrupted operation, availability, the acceptability of tariffs, safety) to each concrete type of service [2-4].

Therefore, the main objective of management company is the definition of expectations of the consumers connected with quality of housing-and-communal services and the organization of works so that to reach satisfaction of these expectations. 


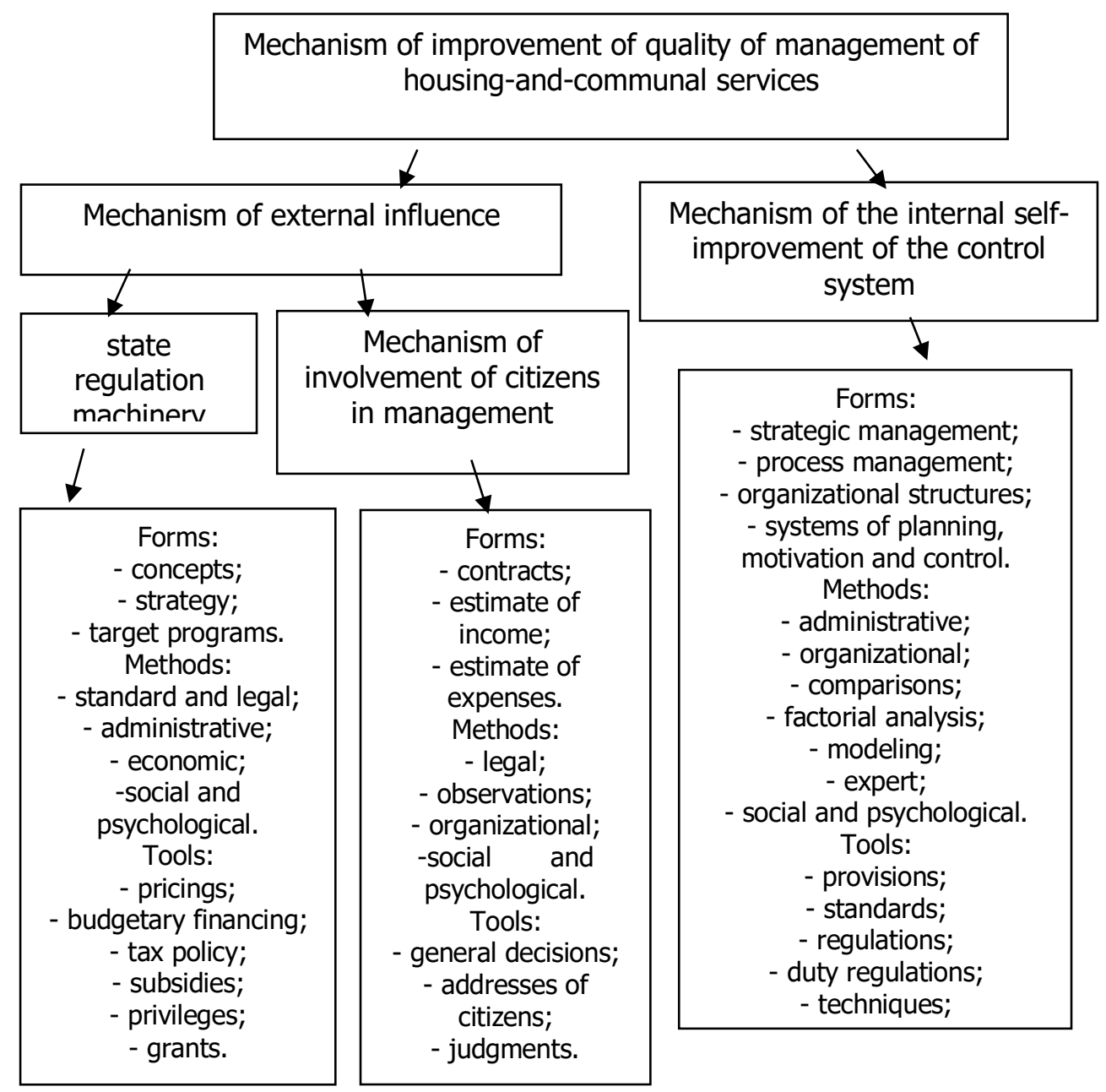

Fig. 2. Structure of the mechanism of improvement of quality of management of housing-andcommunal services (made by the author)

The managing organization acts as the main subject providing directly quality of the housing-and-communal services meeting the requirements of standards [5].

The analysis of techniques of assessment of activity of the management companies offered by Fund of assistance to housing-and-communal services reforming, as well as the authors I.V. Averchev, V.I. Korobko, P.A. Zhadko [6, 7], municipalities of the different cities was carried out (St. Petersburg, Moscow, Volgograd, Vladivostok, Perm, etc.). Research proved that the considered techniques are insufficiently perfect and have some shortcomings. So, in some of techniques, there are no indicators characterizing the quality of the provided services and satisfaction of consumers, some techniques is focused only on the definition of financial performance of activity of the organizations, in the majority of municipal techniques the presented criteria do not characterize either the quality of housing services, or quality of management, or efficiency of activity [8].

Researchers consider that the following principles have to be the cornerstone of the estimates of management quality: orientation to the consumer; scientific validity; complexity of the assessment of the management quality; systemacity; combination of the 
quantitative and qualitative analysis; continuity of implementation of assessment; constant self-assessment of management from the organization; improvement [9].

\section{Conclusions}

The analysis of activity of managing companies proved that, despite their great quantity, all of them have some shortcomings, the lack of standard criteria by which it would be possible to judge about the quality of management.

According to the research, some measures for the improvement of quality of the provided services in the housing-and-municipal sphere were offered.

1. The structural model of management of housing-and-communal services which will allow resolving the contradiction among the purposes of the state (development of the competition in the market of housing-and-communal services), the purposes of commercial organization (making maximum profit) and the purposes of population (receiving highquality and cheap services) is developed.

2. On the basis of the economic interests of subjects of management of housing-andcommunal utilities, the purposes of the increase in the customer satisfaction are formulated.

3. The structure of the mechanism for the improvement of quality of management of housing-and-communal services is developed.

The improvement of quality of the provided services in the housing-and-municipal sphere will ensure the development of this sphere according to the principles of green economy: the use of modern equipment to reduce emissions of pollutants and noise, the introduction of energy and resource saving technologies and renewable energy, reducing the amount of solid waste, accelerated removal and processing of waste. All these measures contribute to improving the quality of life and living environment in the city.

\section{References}

1. I. Togunov, New in the theory of the organization: fractal and facet models, Monograph (Vladimir, Cathedral, 2009)

2. R. Buckley, J. Kalarical, Housing policy in Developing Countries: Conjectures and Refutations (Oxford University Press, IBRD, The World Bank, 2005)

3. J. Smith, S., Elsinga, M., Fox O’Mahony, L., Ong, S. E., Wachter, S. és Hamnett, C. (eds.) International Encyclopedia of Housing and Home, 3 (Oxford, Elsevier, 2012)

4. R. Hunt, Strategic management, 3, 46-48 (2011)

5. Y. Galitskova, M. Balzannikov, MATEC Web of Conferences, 196(28), 04025 (2018) DOI: 10.1051/matecconf/201819604025

6. V. V. Zozulya, L. I. Goncharenko, A. V. Zuikov, G. N. Semenova, Journal of Advanced Research in Law and Economics, 8(5), 1629-1633

7. Calderon, Server, The Effects of Infrastructure Development on Growth and Income Distribution. Policy Research Working Paper (World Bank, 2004)

8. N. G Khairullina, O. V. Ustinova, Kh. N. Sadykova, O. V. Tretyakova, Yu. Z. Bogdanova, International Journal of Economics and Financial Issues, 6, S2, 110-116 (2016)

9. T. D. Kosintseva, N. G. Khairullina, I. N. Gluhih, E. N. Pryakhina, A. Y. Nikiforov, A. Y. Bogdanova J.Z., Espacios, 38, 56, 25 (2017) 
